University of Louisville

ThinkIR: The University of Louisville's Institutional Repository

Electronic Theses and Dissertations

$5-2010$

\title{
Unfulfilled potential : a case study of traditional news media and the Internet.
}

Brenna Loraine Angel 1984-

University of Louisville

Follow this and additional works at: https://ir.library.louisville.edu/etd

Part of the Communication Commons

\section{Recommended Citation}

Angel, Brenna Loraine 1984-, "Unfulfilled potential : a case study of traditional news media and the Internet." (2010). Electronic Theses and Dissertations. Paper 41.

https://doi.org/10.18297/etd/41

This Master's Thesis is brought to you for free and open access by ThinkIR: The University of Louisville's Institutional Repository. It has been accepted for inclusion in Electronic Theses and Dissertations by an authorized administrator of ThinkIR: The University of Louisville's Institutional Repository. This title appears here courtesy of the author, who has retained all other copyrights. For more information, please contact thinkir@louisville.edu. 


\title{
UNFULFILLED POTENTIAL:
}

A CASE STUDY OF TRADITIONAL NEWS MEDIA AND THE INTERNET

\author{
By \\ Brenna Loraine Angel \\ B.A., Western Kentucky University, 2006
}

\begin{abstract}
A Thesis
Submitted to the Faculty of the Graduate School of the University of Louisville in Partial Fulfillment of the Requirements for the Degree of
\end{abstract}

Master of Arts

Department of Communication University of Louisville

Louisville, Kentucky

May 2010 
UNFULFILLED POTENTIAL:

A CASE STUDY OF TRADITIONAL NEWS MEDIA AND THE INTERNET

By

Brenna Loraine Angel

B.A., Western Kentucky University, 2006

A Thesis Approved on

May 8, 2010

By the following Thesis Committee:

Thesis Diretrof 


\section{DEDICATION}

This thesis is dedicated to my mother and husband

for always supporting me

in reaching my personal, professional, and academic goals. 


\section{ACKNOWLEDGEMENTS}

I would like to thank Dr. Jennifer Gregg for her guidance, patience, and support through my thesis journey. I would also like to thank my other committee members, Dr. John Ferré and Dr. Jason Gainous for reviewing my thesis and offering suggestions for improvement.

My interest in Internet journalism was initially sparked as an undergraduate at Western Kentucky University. I credit the faculty of the WKU School of Journalism and Broadcasting for laying the foundation of my journalism training.

Finally, I would like to thank the news staff at WHAS-AM, who allowed me to experiment with many online storytelling techniques on the station website. 


\section{ABSTRACT \\ UNFULFILLED POTENTIAL: \\ A CASE STUDY OF TRADITIONAL NEWS MEDIA AND THE INTERNET \\ Brenna L. Angel}

May 8, 2010

The Internet offers a tremendous opportunity for traditional media to expand and/or enhance news stories. This thesis is an exploration of the convergent journalism practices of three news organizations in a medium-sized market. It employed content analysis and in-depth interviews to compare the news stories of a newspaper, television station, and radio station with content on each organization's Internet website.

While the three media organizations in this case study had different approaches to convergent journalism, they each utilized some type of multimedia technique on their websites including slideshows, videos, audio, hyperlinks, and reader interactivity. For the most part, however, online news stories were replications of their traditional counterparts. Major factors affecting how traditional media used the Internet to tell news stories included available resources, training, and organizational priorities. Some news stories, such as breaking news topics and sports, appear to be more likely to utilize elements of convergent journalism. 


\section{TABLE OF CONTENTS}

PAGE

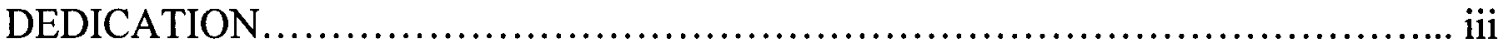

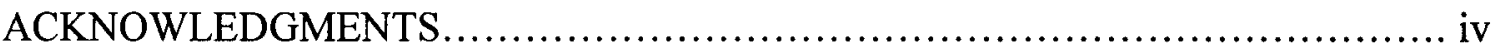

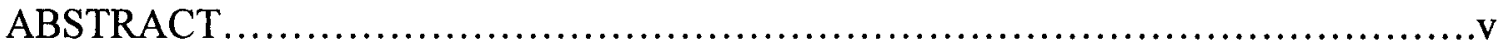

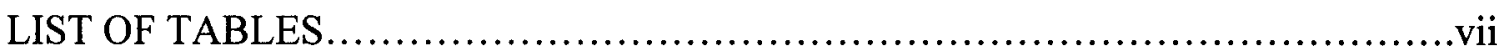

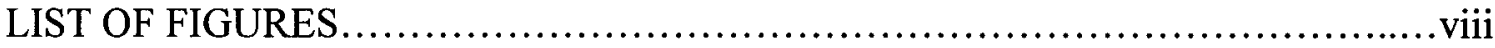

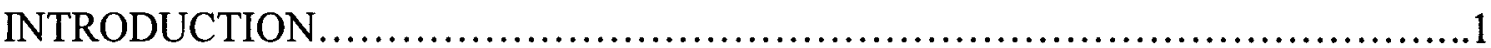

LITERATURE REVIEW .........................................................

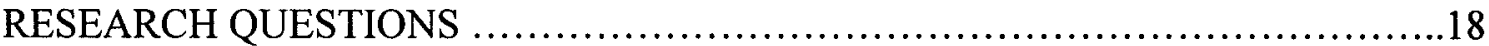

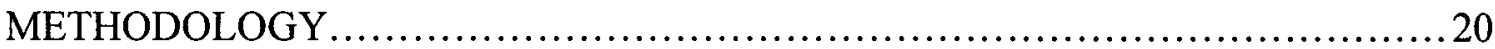

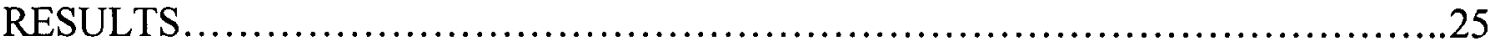

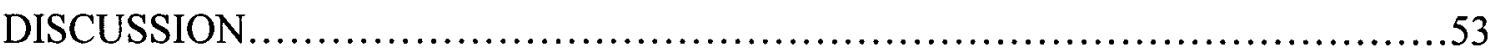

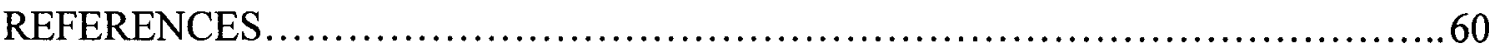

CURRICULUM VITAE ..............................................................66 


\section{LIST OF TABLES}

$\begin{array}{ll}\text { TABLE } & \text { PAGE }\end{array}$

1. Story Elements of Herald-Leader and Kentucky.com Stories........................................36

2. Story Elements of WTVQ-TV and wtvq.com Stories................................................39

3. Story Elements of WEKU-FM and weku.fm Stories.................................................. 41 


\section{LIST OF FIGURES}

FIGURE

PAGE

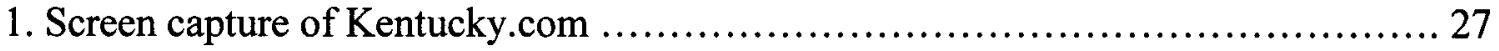

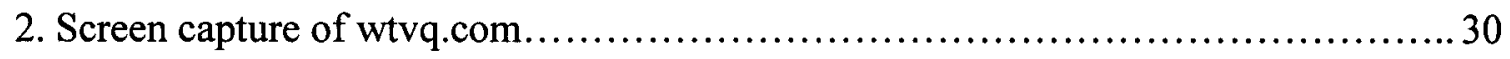

3. Screen capture of weku.fm............................................. 32

4. Screen capture of Lexgo.com theatre story..................................... 35

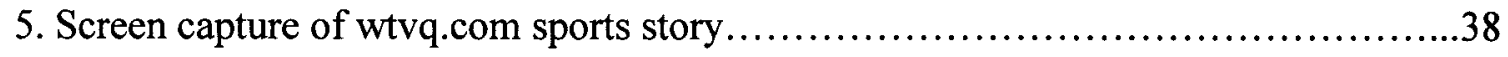

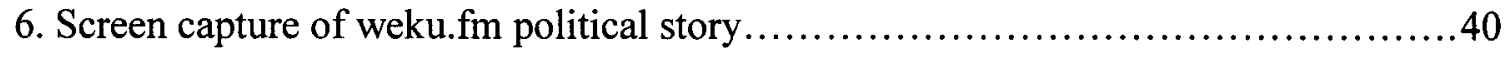

7. Screen capture of wtvq.com health story .......................................51 


\section{INTRODUCTION}

There was a time when a person's choice for information about news and daily events depended largely on how he or she wanted to receive that information. Newspapers were ideal for in-depth written reports, radio for immediate audio information, and television for dynamic video of the people and places being covered. Readers and audience members would possibly have to go to multiple news outlets to find all the information they wanted.

With the emergence of the Internet and mobile Internet devices, however, traditional media are breaking past their conventional boundaries and storytelling limitations by engaging in convergence, the production of multimedia reports available to the news consumer virtually anywhere, anytime. An online report can feature different elements, including written text, a narrated slideshow, graphics, and video. Furthermore, the Internet allows for two-way communication between the reporter and the audience, or between multiple audience members. Mass media scholars predicted the Internet's storytelling potential (Neuman, 1991) even before the term "Internet" became part of mainstream vocabulary. As the technology developed, researchers (Pavlik, 2001; Gunter, 2003; Kawamoto, 2003) have explained the specific practices that are possible with Internet journalism and identified real examples of those practices in use.

Now nearly a decade into the $21^{\text {st }}$ century, are news organizations fully capitalizing on the promise of the Internet? This case study explores the process of "old- 
to-new" convergent journalism. No longer is the general understanding of the Internet limited to a simple repackaging of conventional news reports for a digital venue.

I chose this avenue of research because of the impact the Internet has had on my personal and professional life. I can vividly remember the day my elementary school class was taken to a new computer lab at school, and being instructed by the librarian on how to execute a basic search on something called a "search engine." Years later, as a professional radio journalist, I experienced a slight change in job duties because of the expanding role of the Internet in the news industry. No longer do I file a story only for use on radio airwaves; the story must also be posted to my station's website and on relevant social networking websites.

I used multiple research techniques to analyze how traditional media are using the Internet and why those decisions were made. The findings indicate that while newspaper, radio, and television journalists appear to understand the potential of new media, little is done to make the most of that potential. Hindrances to convergent journalism include time constraints, lack of resources, and lack of motivation to change traditional reporting habits. 


\section{LITERATURE REVIEW}

\section{Online Journalism Beginnings}

Modern online communication, as it is currently known, stems from a technology called videotex. Carlson (2003) defines videotex systems as:

interactive, computer-based systems that electronically deliver text, numbers, and graphics for display on a television set, video monitor, or personal computer. The data travels over telephone lines, two-way cable, computer networks, wireless data networks, or any combination of the four. (p. 35)

In the early 1980s many U.S. newspaper companies experienced colossal failures with videotex systems delivered to specially equipped television sets (Carlson, 2003). The emergence of personal computers made online journalism more feasible, beginning with computer bulletin board systems and eventually shifting to the World Wide Web.

By the late 1990s, newspapers worked to develop an online identity, but that was not an easy process. In an ethnographic study of the Technology section of the New York Times website, Boczkowski (2004) found that understanding an online environment of immediacy, interactivity, and multimedia was difficult for print journalists unfamiliar with audio/video technology. Organizations struggled to learn about the World Wide Web system their audiences were spending increasing time with.

The turn of the $21^{\text {st }}$ century saw even more people using the Internet. For many Americans, the World Wide Web is a regular part of everyday life, so much so that it is 
"in danger of being ignored as boring" (Haythornthwaite \& Wellman, 2002, p. 7).

Turning on the computer and getting online is no longer a special, privileged activity.

People habitually use the Internet to communicate with others, shop, and gather information such as daily news.

Indeed, the Internet is a growing source of news for many Americans, having surpassed newspapers and radio, and shortened the gap with television news in terms of popularity of platform. According to a 2010 study by the Pew Internet $\&$ American Life Project, $61 \%$ of surveyed American adults said they get some kind of news online, compared to $78 \%$ from a local TV station, $73 \%$ from a national TV network, $54 \%$ from radio, and 50\% from a local newspaper. These data appear to support Merrill and Lowenstein's (1971, as cited in Neuman, 1991) theory of media evolution, whereby a new medium is developed and adopted by a mass audience so that it becomes competitive with older media. The older media must then specialize or find some other way to survive.

In October 2009, a leading trade organization changed its name to reflect the changing landscape of journalism. Sixty-three years after its inception, the Radio Television News Directors Association, or RTNDA, declared that the organization would now be known as the Radio Television Digital News Association, or RTDNA. In a letter to members, Executive Director Jane Nassiri (2009) explained, "The digital future is really a future no longer. The change is here - change you're all familiar with in your newsrooms." Nassiri went on to say, "The centerpiece of our services is our website," a statement that may also hold true for the RTDNA's members. For whatever reasons a 
news organization chooses to engage in online journalism, keeping up with audience and industry trends is certainly among them.

\section{Convergence Defined}

A debated topic of discussion for social science researchers is the definition of convergence. Aaron (2002, as cited in Dupagne \& Garrison, 2006) notes that convergence can also be considered "a single business operating with multiple platforms: common management, ads sold across multiple media, and a shared news operation" ( $\mathrm{p}$. 239). An example of this definition is a company that operates two or more traditional media under a single management team.

Lawson-Borders (2003) identifies convergence as "the blending of old media (e.g. magazines, newspapers, television, cable, and radio) with new media (computers and the Internet) to deliver content" (p. 92). Thus, even in the most basic function of replicating traditional news content, journalism websites are a form of convergence.

And still another, slightly different definition is that convergence is a type of journalism in which news is reported for "multiple media platforms such as television, newspaper, the internet and radio" (Huang, Rademakers, Fayemiwo, \& Dunlap, 2004, p. 73). Three operational frameworks have emerged that reflect the different definitions of convergence: (1) the convergence continuum, (2) the cross-media model and integrated model, and (3) the cross-media work axis and content axis.

Dailey, Demo, and Spillman (2005) developed a media "convergence continuum," showing five stages of behavior among news organizations. The activities include (1) cross promotion between media partners; (2) cloning, or unedited replication of a media partner's content; (3) "coopetition," in which media partners share information but still 
produce their own individual content; (4) content sharing, where media partner meet regularly to exchange ideas for special projects; and (5) full convergence, by which media partners share managers and team members. The convergence continuum is limited, however, to working relationships between two or more news organizations. Dailey, Demo, and Spillman did not model it to be used as a way of describing convergence within a single news outlet.

García Avilés and Carvajal's (2009) perspective on news convergence involves two different models: the cross-media model and the integrated model. Through analysis of two Spanish newsrooms, the researchers identify cross-media convergence as a strategy "where multimedia production based on synergies is the desired ideal" (p. 235). The cross-media model appears to parallel the convergence continuum. García Avilés and Carvajal's integrated model, however, describes higher-level convergence focused on content, immediacy, and versatility: "Reporters cover any event for all platforms, and it is assumed that they will exercise skills in video editing, recording, voice-over narration and web publishing" (p. 236).

Erdal (2009) also addresses the limitation of the convergence continuum by crafting a "model of cross-media journalism where two axes exist simultaneously: the work axis and the content axis, each axis moving towards increasing complexity" ( $\mathrm{p}$. 192). Erdal's work axis consists of three categories: (1) single-reporter multiplatform journalism, in which a journalist reports the same story for different media platforms; (2) cross-media coordination, where members of different media platforms share information; and (3) multiplatform orchestration, where reporters and staff from different media platforms cooperate fully with each other to cover a story. While Erdal's work axis 
focuses on human behavior, the content axis classifies how news material is translated from one media platform to another. It also consists of three categories: (1) rhetoric of augmentation, how content is republished largely unedited, such as from a TV format to a Web version; (2) rhetoric of reversioning, involving the transcription or editing of broadcast television or radio material for another platform such as a Website; and (3) rhetoric of recombination, where parts of raw news reports are put together in a different context. Erdal's model is superior to the convergence continuum, the cross-media model, and the integrated model because it appears to account for all of the types of situations where convergent journalism can operate.

The different convergence models represent two major parts of convergence journalism research: journalism as a merger of news organizations and journalism as a merger of old and new technology. Within both of these realms, however, other major issues surrounding convergent journalism include business models, newsroom culture, journalism education, and news content. For the purposes of this case study, the researcher focused specifically on convergence of technology (specifically, use of the Internet) and its effect on journalism practices. Nevertheless, research on organizational convergence is included in this paper because of the current uncertainty of U.S. governmental regulations and the role the Internet plays in those regulatory discussions. Merged newsrooms still exist in the United States, and that number may indeed expand in the future. 


\section{Convergence of Organizations}

Much of what social scientists have learned about convergent journalism has come from situations where media cross-ownership exists in the same market, namely Tampa, Florida (where Media General owns the Tampa Tribune and WFLA-TV) and Chicago, Illinois (where Tribune Company owns the Chicago Tribune, WGN-TV, and WGN-AM). The Federal Communications Commission's 1975 cross-ownership rule prohibits a single company from operating a newspaper and a television station (or radio station, or any other combination of the three traditional media) in the same market. Companies such as Media General and Tribune Company are allowed to maintain their newspaper-broadcast ownership because their situation was already in place before the 1975 ban.

In December 2007 the FCC loosened the rule by allowing cross-ownership in the top 20 media markets in the United States under certain conditions. Legal challenges and criticism of that decision soon followed. In May 2008 the U.S. Senate voted to invalidate the new rule, saying it would lead to "a lack of localism and diversity" in news reporting (Eggerton, 2008). On the other hand, many media representatives support lifting the ban on cross-ownership in some markets, and say the rule actually doesn't go far enough. According to Eggerton (2009), "broadcasters have argued that in an increasingly multiplatform world, where broadcast-online-print synergies may be one way of remaking their business models, the restrictions on cross-ownership are even less defensible."

The cross-ownership debate continues in federal court. On March 23, 2010 the Third Circuit Court of Appeals lifted its stay on the media cross-ownership rule, 
presumably allowing companies in the top 20 U.S. markets to continue moving forward with any plans to operate multiple media outlets in the same city. FCC Commissioner Robert McDowell stated that the court's ruling was "particularly appropriate given the economic upheaval affecting the ongoing viability of many daily newspapers and broadcast stations" (Federal Communications Commission, 2010). This year the FCC is hosting a series of forums and panel discussions about cross-ownership at cities across the country.

\section{Convergence Potential}

Although relaxation of the media cross-ownership rule remains in limbo, the Internet has fueled journalism convergence in every media market, regardless of size. A major theme in the literature about convergence is the potential of the Internet to transform traditional news reporting.

Gunter (2003) identified seven key differences between old and new media: (1) amount of content, (2) format and design, (3) access and customization, (4) immediacy, (5) hyperlinking, (6) interactivity, and (7) cost.

The Internet allows for publication of additional and archived content that would not fit in the space/time available in traditional media. Online news reports are not restricted to a particular format; they can involve text, pictures, audio, video, and more. The news consumer has greater access to Internet news, rather than having to wait for a particular broadcast. Utilizing the Internet also means that news outlets themselves do not have to wait for traditional broadcast/publication to break a story. Through hyperlinks, the Internet allows users to connect to other online content. And unlike traditional media, 
the Internet makes two-way communication possible between news staff and news consumers via e-mail, chat rooms, and instant comment sections. Finally, online news stories typically cost less to produce than traditional ones, particularly newspaper stories. The news industry, however, has not settled on a successful convergence business model. News organizations have been taking advantage of the Internet's potential for years. In 1998, APB Online posted 1,275 pages from a Frank Sinatra file released by the FBI on its website (APB Online, 1998). CNN's online report of a deadly fire at a Rhode Island nightclub in 2003 incorporated a wide range of content, including multiple video clips, three picture galleries, a sidebar of story bullet points, an interactive diagram of the nightclub, and links to related stories (Kawamoto, 2003).

Many of the seven Internet characteristics described by Gunter allow for multimedia storytelling. Thurman and Lupton (2008) conducted in-depth interviews with nine editors and managers of British news websites about multimedia storytelling, focusing mainly on the use of video. The interview subjects yielded several opinions about the use of video in online news stories: video should serve as a complement to the written story, not a mere replication of it; some journalists should minimize their role on camera; and videos should involve short clips that can be easily shared. Thurman and Lupton concluded that while traditional news managers are willing to experiment with multimedia content, a great deal of uncertainty remains about which online storytelling elements and techniques best enhance news reports.

With the Internet, journalists are capable of providing additional information, enhancing their storytelling, and improving interactivity with the audience. This 
potential, however, does not negate the value of traditional news media. As Kawamoto (2003) explains, newspaper, television, and radio still serve important functions: People driving to and from work are not going to be surfing the Web for news. Other times people prefer hard copies of the news media or just to sit back on a couch and watch television. But where context and completeness are concerned, it is difficult to image, at present, a medium with more potential than the Web. (p. 180)

\section{Culture of Convergence}

At the onset of convergent journalism, and especially in situations where crossownership existed, reporters from different specialties (print, radio, and television) had some growing pains in learning to work together. Convergence is generally a top-down initiative. According to journalists Singer (2004) surveyed, "Converging newsroom operations was something their bosses and their bosses' bosses wanted to do-and it was not contestable" (p. 13).

Furthermore, it is against a journalist's instincts to share information or sources. Lawson-Borders (2006) was told by a Dallas TV news executive:

You have a very long history of people in this newsroom, WFAA, wanting to absolutely annihilate any other media competitor to be first on the scene and to be the first to report a story. You have people at the Dallas Morning News who want to do the same thing, and being jointly owned you had a company across the street, I mean literally across the street, that said "thou should not talk to the other property." ... So you have this alley, this driveway, that really was a raging river 
that no one tried to cross and then suddenly the waters were parted and we were told it was okay to talk and there was great trepidation. (p. 141)

Duhe, Mortimer, and Chow (2004) found the concept of a team environment could eventually catch on. A print reporter may have more working knowledge of accessing public records, while a journalist with television experience may have a better eye for making a story more engaging for the audience. It should be noted, however, that Duhe et al.'s research focused on a 2002 survey of U.S. television news directors, and not necessarily the reporters and editors primarily responsible for producing news content.

In an application of diffusion of innovations theory, Singer (2004) also discovered the existence of a cultural clash between journalists with different backgrounds. After spending a week at four converged newsrooms of varying sizes, Singer concluded that smaller organizations and those that had been implementing convergence for a longer period of time seemed to be more comfortable with and accepting of the practice. In larger markets, journalists were more physically distant from their cross-media counterpart, thus making it difficult to develop a strong working relationship.

Despite being a management-created initiative, reporters generally view convergence as a positive aspect of their career development (Duhe et al., 2004; Huang, Davison, Shreve, Davis, Bettendorf, \& Nair, 2006; Quinn, 2006). In knowing how to tell a story across multiple platforms, one interviewee told Quinn (2006), "I think that it makes me more marketable as a journalist. With the way that the job market can be or the economy, I may not always have the dream job I have now" (p. 77). Convergence can allow reporters to expand their skill set, but the issue still remains as to who will teach those skills. 
With technology constantly changing, journalists want more workplace training and less pressure from company management (Duhe et al., 2004) to learn multimedia storytelling. What's more, the change in workload and skill set is not expected to lead to any sort of meaningful salary increase for journalists (Singer, 2004; García Alvilés \& Carvajal, 2009). For many working in the news media, convergence, particularly in terms of online storytelling, is now simply part of the job description.

Just as news professionals face the challenge of learning new skills to publish their stories across multiple platforms, educators are also grappling with how to address the convergence phenomenon. Many journalism schools still divide the specialties of print, photo, and broadcasting into separate course tracks, but that is beginning to change. At the University of Kansas, Quinn (2006) found that professors do not necessarily want to turn their students into an "Inspector Gadget," but they do want to expose their students to different journalism platforms.

In a survey of online news editors, Fahmy (2008) concluded the demand for knowledge in Internet publishing and digital editing will continue to grow, but there will need to be a continued concentration on the ability to write quality news stories. After surveying dozens of journalism educators and news professionals, Huang et al. (2006) noted that "Apart from teaching students multimedia productions, new technology, and computer-assisted reporter, J-schools still need to place good writing - the very basics of being a journalist - as the top priority for all journalism students regardless of sequences or specializations" (p. 255). 


\section{The Business of Convergence}

Through convergence of technology, news companies are able to expand their advertising packages to include websites, although the parent news outlet (print, TV, or radio) remains the major source of ad revenue. A reliable, profitable business model for utilizing convergence remains to be developed.

According to Carlson (2003) online content must be free to consumers unless it is very specialized and in high demand (such as a financial or business publication like the Wall Street Journal). Some news organizations have found that a hybrid revenue strategy works for them, where a portion of the content is free for the public to access, while premium content such as streaming video requires a subscription or some form of payment (Salwen, Garrison, \& Driscoll, 2005).

The issue of a successful convergent business model is further complicated by the volatility of the entire news industry in a slumping economy. Newspaper companies eliminated 109,500 jobs and magazines cut 19,400 positions between January 2005 and January 2010 (Ives 2010). Thus the effort to blaze a convergent journalism trail on the Internet may have slowed as media companies try to survive in their traditional form.

Pavlik (2001) says media executives, critics, and researchers must be patient and realistic in experimenting with online journalism business models. He cites the development of USA Today, a national newspaper introduced in 1984. It took ten years for the paper to become profitable and even longer to gain worldwide respect and credibility as a news source. Pavlik says no less should be expected of the Internet. 


\section{Quality Journalism}

The characteristics and responsibilities of quality journalism have not changed with advancing technology. The Hutchins Commission Report (1947, as cited in Baker, 2002, pp. 154-155) identifies five responsibilities of the press: (1) provide "a truthful, comprehensive, and intelligent account of the day's events in a context which gives them meaning"; (2) be "a forum for the exchange of comment and criticism"; (3) portray "a representative picture of the constituent groups in the society; (4) "present[] and clarify[] the goals and values of the society; and (5) provide "full access to the day's intelligence." More than sixty years after the Hutchins Commission was formed, online journalism has the potential to fulfill all five of the responsibilities.

The Internet platform gives journalists the freedom to incorporate more detailed elements into their stories such as video, audio, and hyperlinks. Pavlik says that Internet storytelling "empower[s] participants in the process of contextualized journalism" by offering the audience "a complex blend of perspectives on news stories and events that will be far more textured than any single point of view could ever achieve" (2001, p. 24).

The abundance of online information available to news consumers has generated different opinions. On one hand, it gives consumers greater freedom and choice of news products. They no longer have to sit through an entire television broadcast to watch a particular story, nor are they limited to the amount of information printed in the newspaper or broadcast over the air. The Internet allows consumers to choose particular elements and customize their news gathering experience.

But all the content available on the Internet could inundate and frustrate readers, especially those seeking the basic facts of a story. Freedom of news choice could also 
mean that sound editorial decision-making by news reporters and mangers will be unnecessary. According to Kawamoto, "a free and democratic society is better off risking information overload than risking information scarcity" (2003, p. 169). And Neuman foresees that news media will continue to set the agenda:

Packaging, formatting, filtering, and interpreting complex flows of information represent value-added components of public communications. In a more competitive, complex, and intense communications environment, that value-added component will be equally important to the individual citizen, if not more so. (1991, p. 163)

Although many studies have analyzed the processes and operations of convergent journalism, few have examined what effect convergence has on the overall product. In a review of Tampa Tribune newspaper articles, Huang et al. (2004) attempted to measure the quality of journalism produced in a converged newsroom. Compared to news reports written prior to the converged journalism model taking effect, researchers found that news characteristics and elements such as enterprise, fairness and balance, authoritativeness, and localization remained the same. Use of the Internet to publish stories appeared to cause a heightened sense of urgency and greater audience awareness among reporters.

In contrast to the previously mentioned case studies centered on organizations in large markets, Smith, Tanner, \& Duhé (2007) surveyed reporters and producers in small and medium local television markets. Their findings were striking: television staff were producing little to no new material for the TV station's website. "Very few respondents said they provided still pictures, added additional facts, or posted links for stories on the 
Web. Not a single person said he or she created an Internet-only story" (p. 569). Such findings are alarming because they indicate that journalists (in this case, small and medium market television journalists) are not utilizing the Internet to its full storytelling potential. Smith et al. speculated that a lack of time, funding, and staff resources contribute to the problem, but their study was limited to survey responses and did not include in-depth interviews or content analysis. 


\section{RESEARCH QUESTIONS}

In the midst of an economic downtown that has forced companies to downsized, news organizations must not lose sight of the basics of good journalism. News reports should still be factual, balanced, timely, proofread, and include the relevant who, what, where, and when information. With convergent journalism, expanded Internet reports might include hypertext links to other relevant articles, a clickable map of the particular geographic region, a historical timeline, a photo gallery, a slideshow, audio, video, or downloadable files (Kawamoto, 2003). Furthermore, portable digital devices and interactive television allow for immediate publishing of breaking news alerts, communication between readers and viewers, and greater user-control of content presentation (Gordon, 2003).

With all the promise of the Internet, to what extent are media companies engaging in convergence? Is their goal of convergence to enhance journalism quality or to better the company's bottom line? Quinn (2005) says a fundamental dichotomy exists: “a business view of convergence-multiple-platform publishing as a toll for increased productivity and marketing — versus journalists' aspirations in which convergence offers them the potential to do better journalism" (p. 29). To determine if news organizations are making the most of the Internet, the following questions were proposed for this journalism case study: 
1. What elements of convergent journalism are news organizations employing and how?

2. What differences, if any, exist between original news reports on their traditional platform and the digital version?

3. What factors contribute to the convergent journalism decisions that are made?

4. Do certain types of news reports favor certain elements of convergent journalism?

Answers to these questions revealed that online journalism does not measure up to its potential. 


\section{METHODOLOGY}

The purpose of this case study was to determine the extent to which traditional media journalists are utilizing the Internet and other modern mass communication technologies. This goal lends itself to a quantitative approach; that is, determining how many of the radio/TV/newspaper reports on that news organization's website use aspects of convergent/multimedia journalism. However, this study was also concerned with how and why those convergent journalism choices were made. It is one thing to document the occurrence of something, but mass media researchers must also explore the causes of that occurrence. For this reason, a case study methodology was utilized, to account for the contextual conditions of a contemporary phenomenon that can incorporate multiple approaches to data collection (Yin, 1994).

The first aspect of the study utilized content analysis, which Krippendorff defines as "a research technique for making replicable and valid inferences from data to their context" (1980, p. 21). Content analysis has also been defined as "a research technique for the objective, systematic, and quantitative description of the manifest content of communication" (Berelson, 1952, p. 18, as cited in Holsti, 1969). This method of research is ideal because it is unobtrusive and can be used on varying material (such as news reports, which can differ greatly in length, content, and style). Furthermore, the coded material was all publicly available in the form of published or broadcast news reports. 
The research units for this study include one newspaper, the Lexington HeraldLeader; one television news station, WTVQ-TV; and one radio news station, WEKUFM. Owned by the McClatchy Company, the Herald-Leader is the major daily newspaper for the city of Lexington, Kentucky. As of September 2009, the newspaper has an average daily circulation of just under 100,000 (Audit Bureau of Circulations, 2009). The Herald-Leader's website is www.kentucky.com. WTVQ is also based in Lexington, which according to the Nielsen Company has approximately 506,000 television households (Nielsen Company, 2009). WTVQ is an ABC affiliate owned by Morris Multimedia, Inc. The television station's website is www.wtvq.com. WEKU is a 50,000-watt public radio station licensed to Eastern Kentucky University in Richmond, Kentucky. Its programming includes classical music and news broadcast to more than 50,000 listeners (WEKU, 2010). The WEKU website is www.weku.fm.

These news organizations were chosen for specific reasons: (1) they produce original, local content daily for both their traditional platforms and Internet websites, (2) their geographic location was convenient to the researcher, and (3) the researcher-who at the beginning of the study was employed by Clear Channel Radio in Louisville and is currently employed by WUKY radio in Lexington - had not been professionally affiliated with the news organizations at the start of the study. Schwandt defends the use of purposeful sampling of particular units when "there may be good reason to believe that 'what goes on there' is critical to understanding some process or concept, or to testing some established theory" (as cited in Lindlof \& Taylor, 2002, p. 122). The researcher followed the news content of the Herald-Leader, WTVQ, and WEKU for two weeks (14 days). 
Researchers often use sampling as a way to systematically manage vast amount of information being studied. This case study involves the analysis of six units: the three traditional media and their respective websites. Because the content analysis was conducted over a two-week period, a complete census of the data, rather than sampling, was possible. Although this method is time consuming, it is manageable when coding data from a relatively short time frame. A much larger sample size would have called for stratified monthly sampling (Riffe, Lacy, Nagovan, \& Burkum, 1996) or constructed week sampling (Lacy, Riffe, \& Randle, 1998).

Only locally produced stories were considered units of analysis during this case study because these were the stories that local journalists had "control" over. Unlike a wire-service report, network story, or syndicated column, the local journalists decided how to tell their stories and what material to put on the website.

For the Herald-Leader, local stories included general news reports such as crime, politics, business, and sports. Columns and editorials written by local authors were included in the content analysis. Similar locally produced stories broadcast during WTVQ's and WEKU's newscasts were also documented. In other words, a story was considered "locally produced" when that particular news outlet employed the story's author.

It is important to note that this content analysis used a single coder, the researcher. Although intercoder reliability was not an issue for this case study, there still needs to be a consistency in how news content is classified. Lipsey and Wilson (2001) suggest that coders check their work by re-coding the data "after sufficient time has passed so they are not fresh in mind, without reference to the original coding" (p. 86). 
After documenting the stories in their traditional media platform, the researcher then analyzed the corresponding Internet version, if applicable. The presence of convergent journalism elements such as links to other websites, slideshows, audio, video, and databases were noted for each local story. Because this research method is unobtrusive to the media organizations, the analyzed stories were not influenced by reporter/producer knowledge of the ongoing study. The content analysis was used to determine the frequency of categorical occurrences, particularly how often the Internet news stories were simple replication of their original format, and the extent to which each website utilized elements of convergent journalism.

The Human Subjects Protection Program office at the University of Louisville approved this case study for research involving human subjects. Upon completion of the content analysis, the researcher invited journalists and news managers from the newspaper, TV station, and radio station to engage in an individual in-depth interview. From the Herald-Leader, the newspaper's interactive director, editor, and arts/culture reporter were invited, and accepted the interview request. The newspaper's web editor did not return requests for interview made via e-mail and telephone message. The researcher invited three members of the WTVQ-TV staff to participate in the case study: the news director, the assignment manager, and a general assignment reporter. Of the three, only the news director accepted the interview request. From WEKU-FM, the researcher interviewed the station's programming director and news director.

According to Lindlof and Taylor (2002), "Interviews are particularly well suited to understand the social actor's experience and perspective" (p. 173). The interview subjects were informed of the content analysis and were asked to provide insight into 
why decisions were made to use or not use convergent journalism techniques. Because this case study is focused on work related decision-making, names and business titles of the subjects appear in the report. This technique is in keeping with the reporting styles of Lawson-Borders (2006) and Quinn (2006). 


\section{RESULTS}

The content analysis and in-depth interviews revealed that while the three media organizations in this case study had different approaches to convergent journalism, all of them utilized multimedia elements on their websites. These elements included slideshows, videos, audio, hyperlinks, and user comment sections. For the most part, however, online news stories were replications of their traditional counterparts. Major factors affecting how traditional media used the Internet to tell news stories included available resources, training, and organizational priorities. Some news stories, such as breaking news topics and sports, appear to be more likely to utilize elements of convergent journalism.

Question 1: What elements of convergent journalism are news organizations employing and how?

Elements utilized on all three of the news organizations' websites were text, photographs, and hyperlinks. Beyond that, each organization incorporated other elements not necessarily found on the other two media websites. In addition to text, photographs, and hyperlinks, the Lexington Herald-Leader website, Kentucky.com, featured graphics, databases, audio, slideshows, video, downloadable documents, and user comment sections. Wtvq.com, the website for the television station, used video, graphics, interactive graphics, and user comment sections. The additional element present on 
WEKU radio's website, weku.fm, was audio. Both WTVQ and WEKU used their websites to promote content on the traditional broadcast platform.

\section{Lexington Herald-Leader}

The Lexington Herald-Leader has a family of four websites: Kentucky.com, Kentuckysports.com, Lexgo.com, and Bluegrassmoms.com. Figure 1 is a screen capture of the main web page of the Herald-Leader's flagship site, Kentucky.com. The website logo and a search engine are displayed at the top of the page. Below the Kentucky.com logo is a line of "tabs" that correspond to different sections of the website, such as news, sports, classifieds, and opinions. The "find it now" tab features links to blogs written by Herald-Leader staff, and links to Kentuckysports.com, Lexgo.com, and Bluegrassmoms.com. Directly below the tabs and on the far right of the page are logos/links to four web tools where Kentucky.com content can also be found: RSS feed (Really Simple Syndication), my Yahoo (customizable web page), Facebook (social media website), and Twitter (social media website). The center of the page features a picture that changes throughout the day. To the left of the picture are a few local news headlines, each followed by a brief summary of the story. The far right of the Kentucky.com main page features three lists of news stories ranked by the number of views, comments, or reader recommendations. 


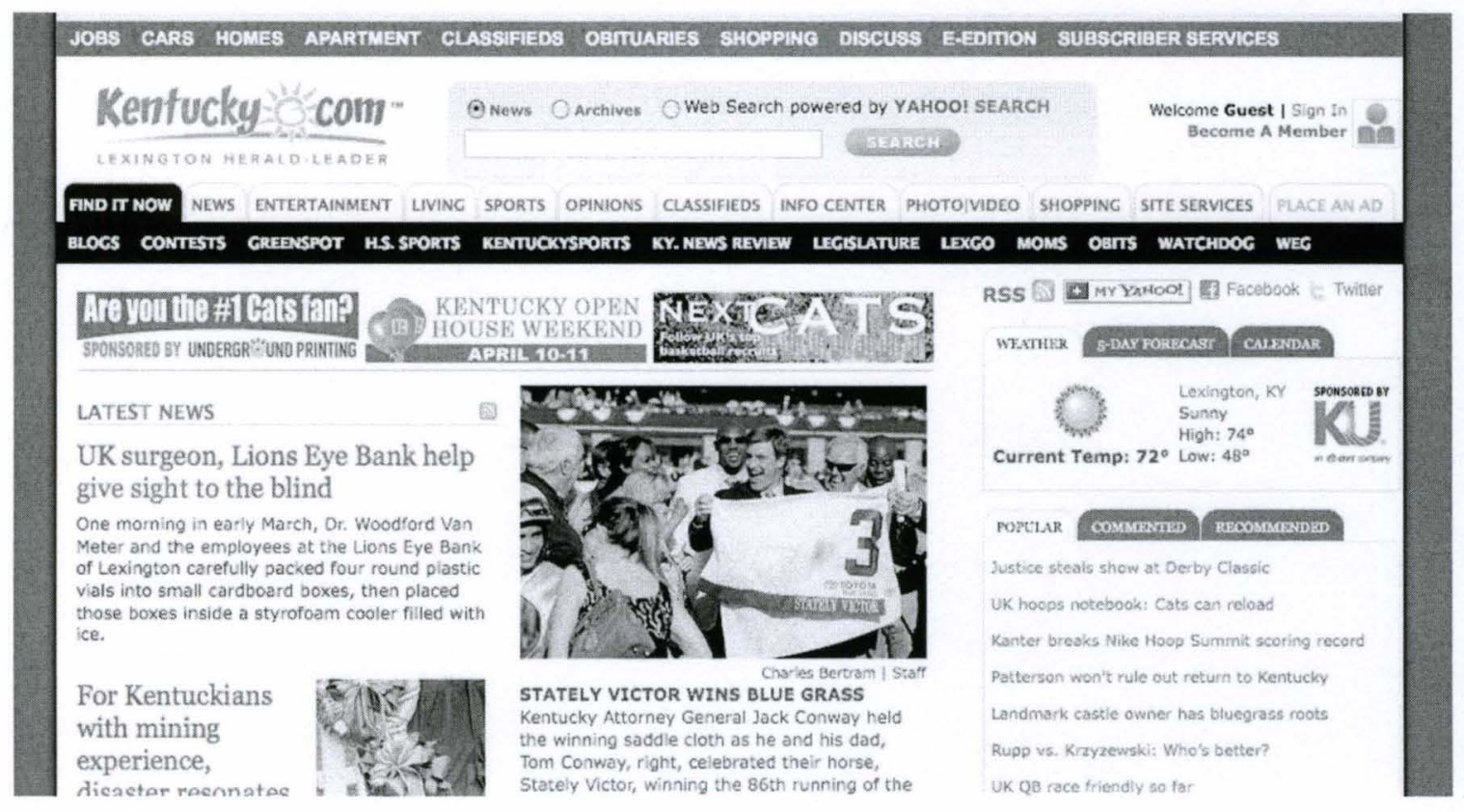

Figure 1. Screen capture of Kentucky.com. This figure illustrates the main page of Kentucky.com, the Herald-Leader's flagship website.

Kentucky.com and other Herald-Leader websites utilized several types of convergent journalism elements. They included: text (present in 338 web stories), user comment sections (338 stories), photographs (159 stories), graphics (73 stories), links to other websites (45 stories), slideshows ( 9 stories), video (5 stories), online databases (4 stories), audio (4 stories), and downloadable documents (4 stories).

The online elements were embedded within the online news story. Any story with text also had a user comment section, most likely because it was automatically generated by the newspaper's website software. The ten web stories that did not include text and a user comment section were the locally produced political cartoons. The 159 web stories with at least one photograph had individual pictures with captions that website users could click on. Slideshows, on the other hand, were self-contained media that 
automatically progressed from picture to picture (although the user could pause the slideshow and manually click to change pictures). With the exception of two slideshows-one slideshow embedded with a weather-related story and the other incorporated into a story about a theater production-- the slideshows mainly pertained to sports, particularly sports at the University of Kentucky.

Graphics were present in 73 web stories in the form of informational boxes. The video files embedded into five stories varied in production quality: one featured undercover video footage; one file had high definition video with several transitions; and three stories contained videos clips from an interview. The databases incorporated into four stories provided searchable information about pending legislation in the state general assembly and real estate for sale. Other databases available on Kentucky.com (although not incorporated into stories coded during the research period) provide information on public salaries and property values. The downloadable documents used in four web stories took the form of PDFs, generally of large reports or publicly released information. Of the hyperlinks that were included in 45 web stories, some were links to other related stories that were also on the Herald-Leader's website, while other links directed readers to the outside website of a person or organization referenced in the story.

The newspaper also engages in online blogging and social networking. These portions of the websites were not necessarily part of regular news stories and thus were not included in the content analysis. Blogs on the Herald-Leader's website are written by reporters and columnists. Much of the content on the blogs, however, appears to be replication of stories published in the newspaper and on the website. The Herald-Leader uses Facebook and Twitter to post news headlines and links that direct the audience back 
to the main Kentucky.com website. A few reporters and columnists have their own Twitter accounts, which they use to exchange messages with other Twitter users and post comments about people and events that may or may not relate to their latest news story.

WTVQ-TV

The main page of WTVQ's website, wtvq.com, has a similar layout to Kentucky.com. It has the television station's logo positioned in the top left corner of the page. Links to web tools, including Twitter, Facebook, and YouTube, are displayed to the right of the WTVQ ABC 36 logo. Wtvq.com also uses organizational tabs to divide each section of the website, including news, sports, weather, and health. Below the tabs is a search engine where readers can enter keywords to search directly for a particularly story on wtvq.com. The television station's contact information is also displayed on the main page. The center frame on the page features local news headlines. Readers can either position their mouse over the headline to see a large picture and summary of the story, or they can click on the headline to go directly to that story. 


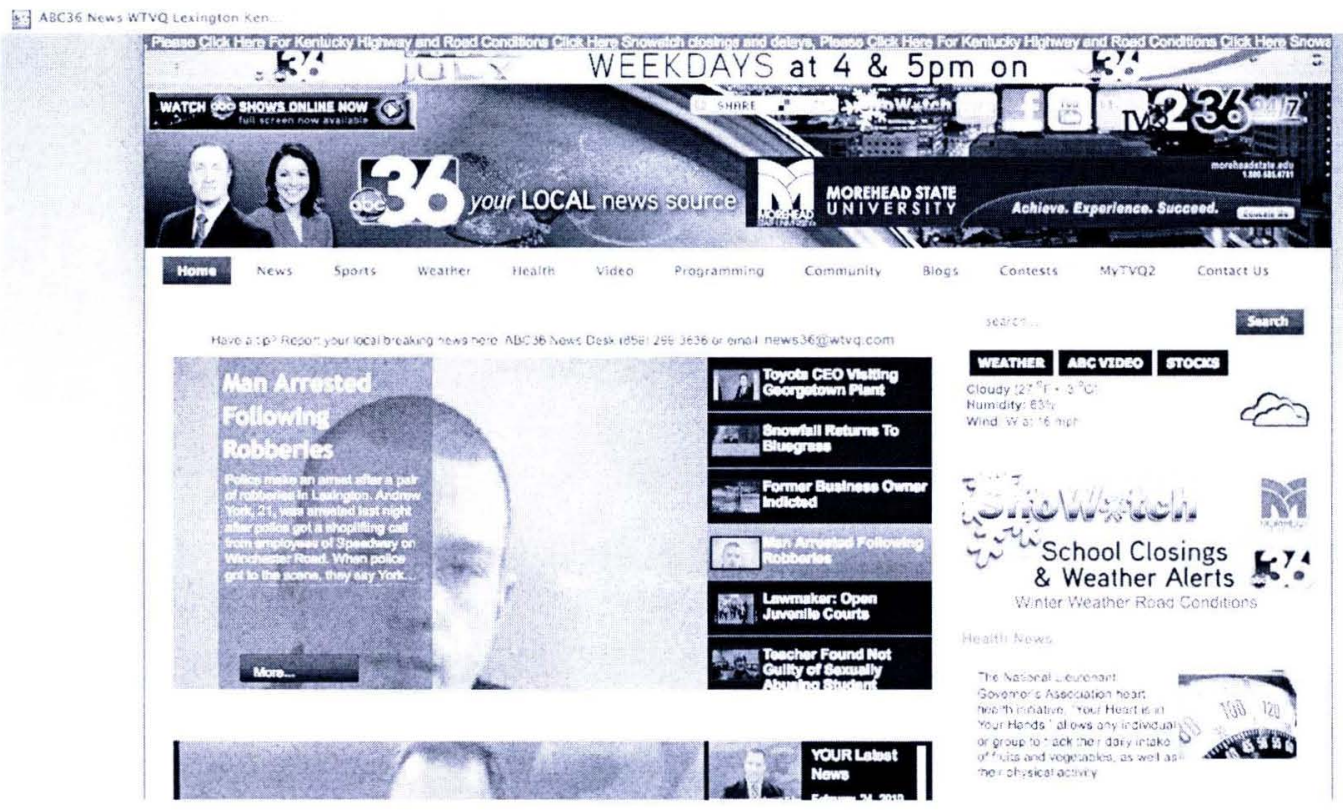

Figure 2. Screen capture of wtvq.com. This figure illustrates the main page of wtvq.com, the website for WTVQ-TV.

Wtvq.com employed several convergent journalism elements. These elements included text (present in 135 stories) photographs ( 96 stories), video ( 77 stories), interactive graphics (21 stories), graphics (15 stories) hyperlinks (19 stories), and user comment sections (105 stories). Two web stories promoted traditional media content.

The text did not have a uniform style. Paragraph spacing varied from story to story, and a small number of stories had grammatical errors. While not all stories with text had a user comment section, the user comment section element was applied only to stories with text. Still photographs (usually a video screen capture) were embedded next to the text of news stories. The video incorporated into 77 stories took several different formats, including reporter package, anchor VO/SOT (voice-over-video and sound-ontape), and a question-and-answer format between an anchor or reporter and an interview subject. Video was generally embedded into a story, but many times the video was 
organized in a separate frame on the WTVQ website. For example, within a single web page, a user could watch a video in one frame and read different news stories in another frame. This setup made it difficult for the researcher to locate both a news story and any corresponding video. The hyperlinks that were incorporated into news stories led to outside sites, such as the website of an organization referenced in the story. The interactive graphics were used on weather forecast stories, where the user could click and zoom in/out on a weather radar map.

WTVQ also utilizes blogs and online social networking, however these were not referenced in individual news stories. There are six blogs on wtvq.com: a weather blog written by the station's meteorologists, a NASCAR blog, a parenting blog, a video game blog, and a beauty/makeup blog, and a blog written by WTVQ's general manager. With the exception of the weather blog, the content of the wtvq.com blogs did not appear to replicate or correspond with other content on the website. Similar to Kentucky.com, WTVQ mainly uses Facebook and Twitter to post headlines of news stories that link back to the main website. Some WTVQ reporters and anchors also have their own individual Twitter accounts to post/comment on news stories.

\section{WEKU-FM}

The website for WEKU radio is weku.fm. At the top of the main web page is a banner featuring the radio station's logo. Directly below this banner is a line of organizational tabs for other sections of the website, including the programming guide, news, and the fine arts calendar. A frame in the far left side of the page displays what programming is currently being aired on the radio station, and a "listen now" link allows 
web users to stream the live radio content on their computer. The center frame of the web page is a column of news headlines, each followed by a one or two sentence summary of the story. Although there are no logos or links on WEKU's main webpage to indicate it, WEKU also uses Facebook and Twitter. News headlines and links are posted on these social networking websites to direct readers back to weku.fm.

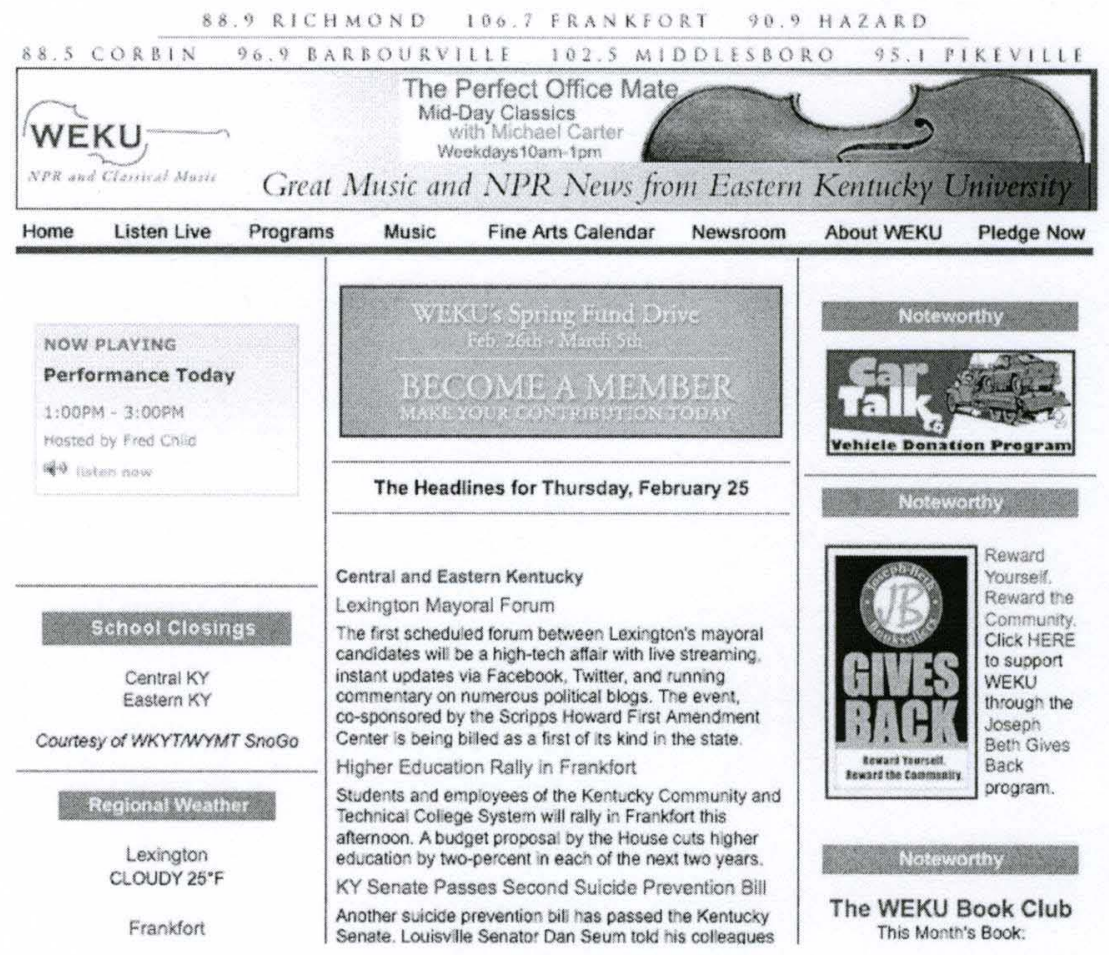

Figure 3. Screen capture of weku.fm. This figure illustrates the main page of weku.fm, the website for WEKU radio.

Of the three media analyzed for this case studied, WEKU incorporated the fewest convergent journalism elements on its website. All 43 web stories incorporated text. Twenty-five stories had embedded audio and 16 stories had an embedded photograph. Only one story analyzed during the research period had a hyperlink to another website. One web story promoted traditional radio content. The photographs were mainly 
headshots of public officials that were the subject of the news stories. It should be noted, however, that the Kentucky General Assembly was in session during the research period, and many of WEKU's stories involved government and legislative figures.

Question 2: What differences, if any, exist between original news reports on their traditional medium and the digital version?

Across all three media studied, few differences existed between reports in their traditional form and reports on the websites. All stories printed in the Herald-Leader were posted to Kentucky.com. The website actually had ten unique stories that did not appear in the newspaper. Significantly fewer individual stories appeared on wtvq.com than were broadcast on the television station. The stories that were posted on the website, however, were replications of the original story. All stories that were broadcast on WEKU were also posted to weku.fm.

\section{Lexington Herald-Leader}

There were few differences between news stories in the print form of the HeraldLeader and their online counterpart. Story headlines in the paper were not always the same on Kentucky.com. For example, a story in the newspaper was headlined, "House takes a whack at state budget" while the same story on the website had a headline of "House proposes cutting 2 school days, university funds." This difference presented a slight challenge to the researcher in locating the correct online story. The researcher 
overcame that challenge by typing text from the newspaper story into an online search engine.

During the research period 348 local stories were printed in the paper and 358 local stories were published on Kentucky.com. The ten extra stories that appeared on the website but not in the newspaper were "Lu-Ann's Kentucky News Review." These web stories are a compilation of news summaries and links to other news websites with Kentucky-related content.

The same number of stories with photographs in the newspaper (159) also had photographs embedded in the web story. While some photographs that appeared in the newspaper were cropped to fit into a certain space, the photographs on the website were posted in their full size. Ninety-one newspaper stories had graphics, compared to 73 online stories. Many times this difference appeared to be the omission of box scores from sports stories.

With the exception of this graphics category, if a difference existed between print and online stories, it involved the inclusion of additional elements not found in the paper (such as audio, video, a slideshow, or user comment section). For example, a February 14 story in the newspaper about a new theatre production included text, an information box graphic, and one photograph. The web version of that story, however, included text, two photographs, audio, links to other websites, and a user comment section. (See Figure 4.) 

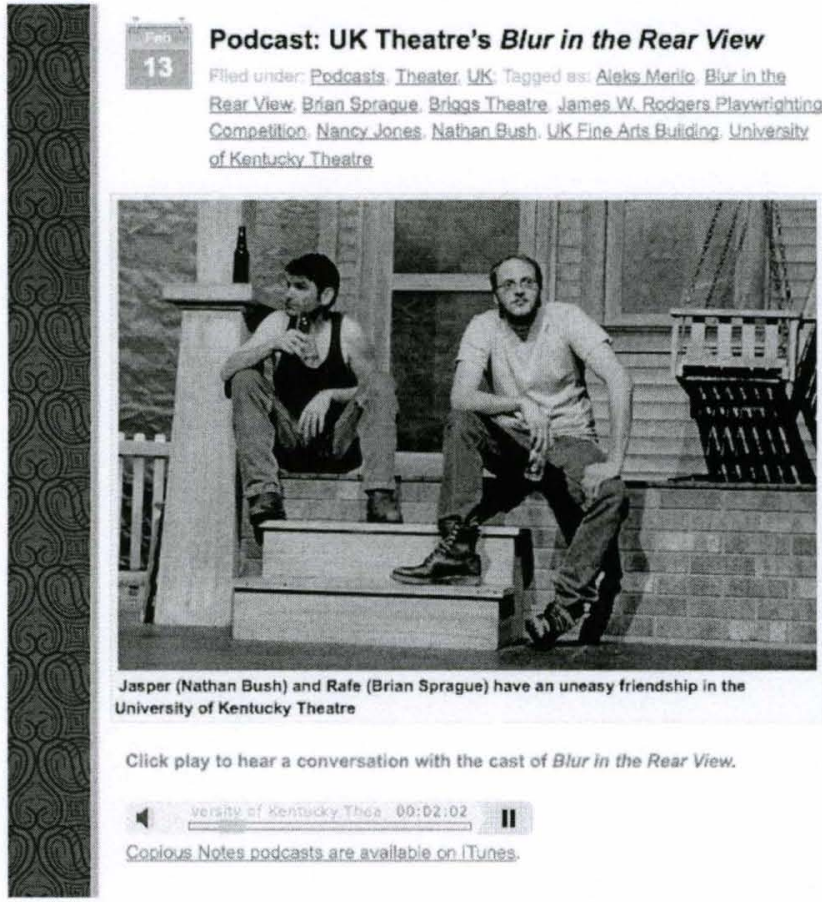

Jasper (Nathan Bush) and Rafe (Brian Sprague) have an uneasy friendship in the University of Kentucky Theatre

Click play to hear a conversation with the cast of Blur in the Rear View.

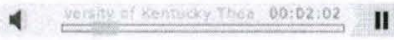

Copious Notes podcasts are available on ITunes.

ป Subscribe to

Copious Notes.

- Preview of Dunbar and Owensboro's SETC shows

- SETC set to invade Lexingtor

Review: Tim McGraw and Lady Antebelum at Rupp Arena

About Rich

Copley \& Copious Notes

Raised by opera-loving parents in a rock ' $n$ ' roll world, Rich Copley has parlayed his broad interests into his career writing about arts and entertainment. Since 1998, he has covered performing arts, film and faith-based popular

culture for the Lexington Herald-Leader, the daily

newspaper in Lexington, Ky. MORE [ E-mail Rich
POWERED BY

Kenfucky com

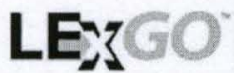

61

(johnelayiv is asking how Cat fans feel about the players' on-court behavior in recent games: hittpiffolt.ly Idincepp

9 days ago

Want to be in a reshoot of @laurabellbundy's "Giddy on Up" video. Here's how: hittp://bit.ly/96E4fi

8 days ago

Running over to the Lexington Art League to Friday secret is: hittpulbitily $196 \mathrm{E} 4 \mathrm{fi}$

8 days ago

Candace says Baiagula Theatre's "No Exit" is

Figure 4. Screen capture of Lexgo.com theatre story. This figure illustrates how an audio file was embedded into a story about a new theatre production.

The most frequent "additional element" incorporated into Herald-Leader website stories was the user comment section, which was embedded into $97 \%$ of online news stories. This web feature allows readers to instantly post their opinion or reaction to the story. Hyperlinks were the second most frequently used web element (12.5\%), followed by slideshows $(2.5 \%)$. A very small percentage of web stories incorporated audio, video, databases, or documents. 
Table 1

Story Elements of Herald-Leader and Kentucky.com Stories

Element

Number of Stories (\% of Total)

\section{Herald-Leader}

Text

Photograph(s)

Graphic(s)

Internet Promo

User Comment Section

Hyperlink(s)

Slideshow

Video(s)

Database

Audio

Document(s)
$338(97.1 \%)$

$159(45.6 \%)$

$91(26.1 \%)$

$21(6 \%)$
Kentucky.com

$348(97.2 \%)$

$159(44.4 \%)$

$73(20.4 \%)$

$348(97.2 \%)$

$45(12.5 \%)$

$9(2.5 \%)$

$5(1.4 \%)$

$4(1 \%)$

$4(1 \%)$

$4(1 \%)$ 
WTVQ-TV

Over the course of the 14-day study, WTVQ aired 303 unique local stories. Because of the nature of broadcast television with several newscasts a day, many stories were repeated, and often in a slightly different format. The researcher was careful to count only unique stories. For purposes of recording specific story elements, the researcher documented whatever format involved the most production. For example, if a story aired in one newscast with a VO/SOT (voice over video and sound-on-tape) but in another newscast used a reporter package, the researcher recorded the story as having used the reporter package.

There were significantly fewer local web stories on wtvq.com (160). Furthermore, while 253 television stories (83\%) incorporated some type of video (Anchor VO, Anchor VO/SOT, reporter package, or Live Q \& A), only 77 web stories (48\%) contained video. The way sports stories were posted to the website likely contributed to this difference. Instead of posting individual sports stories, a single video file of that evening's entire sportscast (typically a four-minute segment) was published to the website. For example, instead of posting an individual web story or video about the highlights from a single basketball game, wtvq.com had highlights from multiple basketball games or sports stories on one video file. See Figure 5. The video that was posted to the website was always an exact replication of what had aired during the broadcast ${ }^{1}$.

\footnotetext{
${ }^{1}$ WTVQ posts a "mini newscast" to its website in the form of a three minute video file. The "ABC 36 News Update" airs throughout the day on WTVQ's third digital channel. Because this content does not appear in the regular newscast, it was not coded.
} 


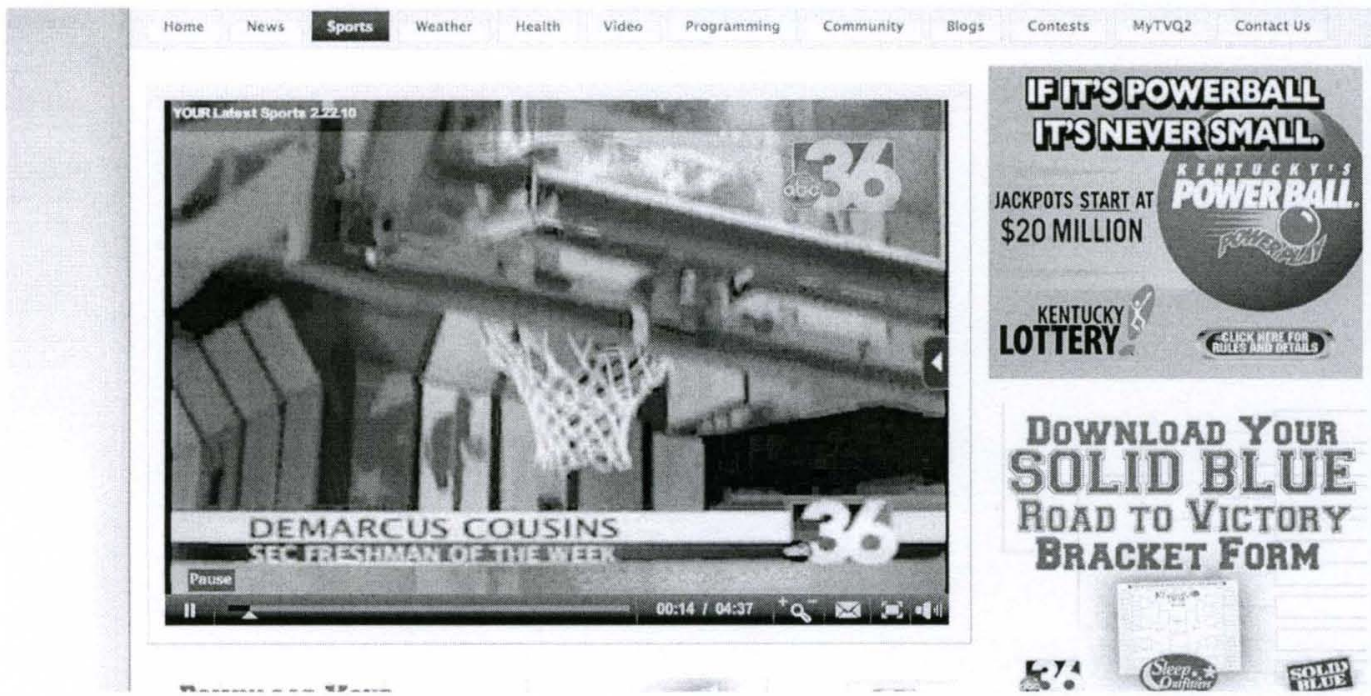

Figure 5. Screen capture of wtvq.com sports story. This figure illustrates how sports stories were posted to the website as a single file, replication of the nightly sports report. 
Table 2

Story Elements of WTVQ-TV and wtvq.com Stories

Element

Number of Stories (\% of Total)

WTVQ-TV

wtvq.com

Anchor VO

$102(33.6 \%)$

Anchor VO/SOT

$63(20.7 \%)$

Reporter Package

$58(19.1 \%)$

Live Q \& A

$30(9.9 \%)$

Internet Promo

$15(4.9 \%)$

Text

$135(84.3 \%)$

User Comment Section

$105(65.6 \%)$

Photograph

$96(60 \%)$

Video

$77(48.1 \%)$

Interactive Graphic(s)

$21(13.1 \%)$

Hyperlink(s)

$19(11.8 \%)$

Graphic

$15(9.3 \%)$

Promote TV Content

$2(1.2 \%)$ 


\section{WEKU-FM}

Because the WEKU website incorporated very few story elements, there were very few differences between the online stories and their original radio form. There were 42 unique on air stories recorded during the 14-day research period, compared to 43 web stories. The extra story posted online corresponded with a longer audio report that did not air during the regular newscasts (WEKU sometimes airs longer audio features outside its local newscasts). While all 42 traditional radio stories incorporated some type of audio (either a sound actuality or a reporter wrap), only 25 web stories had audio. This audio was always in the form of a reporter wrap that had been broadcast.

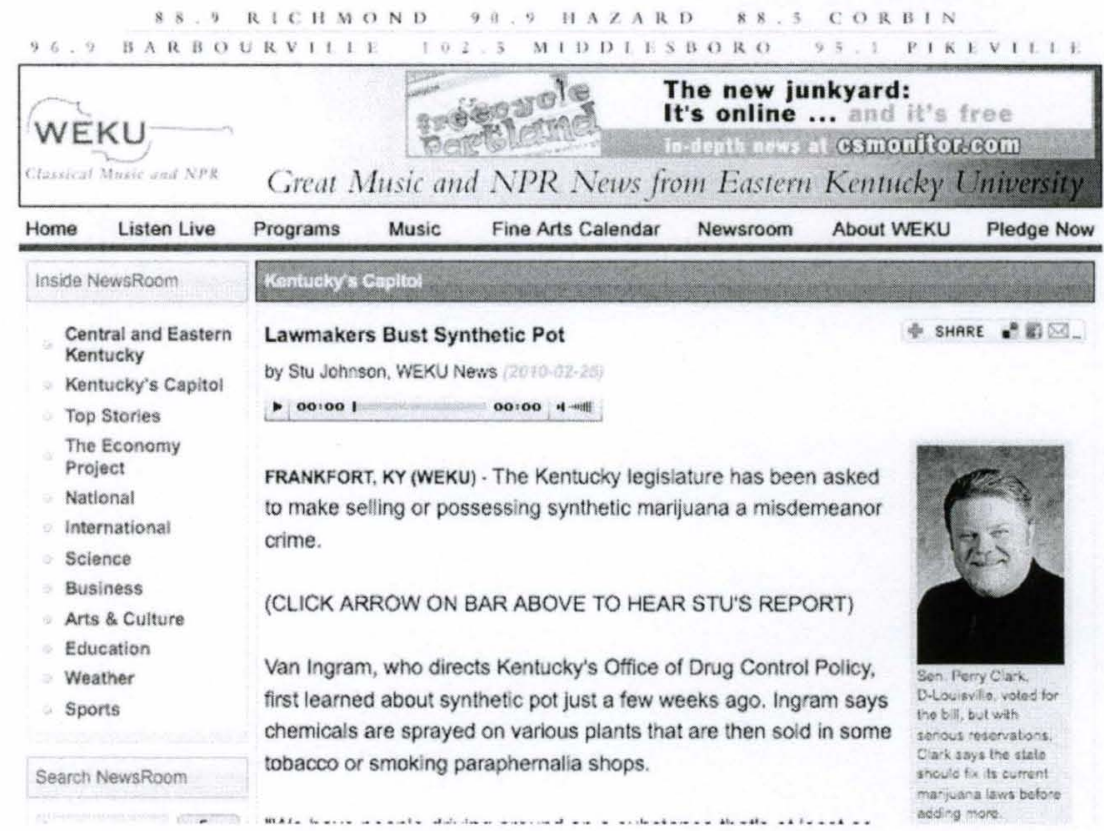

Figure 6. Screen capture of weku.fm political story. This figure illustrates how an audio wrap and photograph were embedded into the story. 
Table 3

Story Elements of WEKU-FM and weku.fm Stories

Element

Number of Stories (\% of Total)

WEKU-FM

weku.fm

Sound actuality

$19(45.2 \%)$

Reporter wrap

$23(54.8 \%)$

Text

$43(100 \%)$

Audio

$25(58.1 \%)$

Photograph

$16(37.2 \%)$

Hyperlink(s)

$1(2.3 \%)$

Promote Radio Content

$1(2.3 \%)$

Question 3: What factors contribute to the convergent journalism decisions that are made?

Each news organization in the case study identified factors and circumstances that affected whether an element was used on a web story. Management at the Herald-Leader expects reporters to look for multimedia opportunities, while management at WTVQ and WEKU place top priority with their traditional media product. All three organizations consider time and resources when producing content for their websites. 


\section{Lexington Herald-Leader}

Several factors contributed to whether a Herald-Leader news story was changed or enhanced for the website, including availability of information, reporter ability, production efficiency, audience traffic, and competitive edge.

Michael Johnson, Interactive Director for the Herald-Leader, says online technology has a storytelling advantage over print:

Online we can enhance... stories with other forms of multimedia, whether it be photo slideshows, photo slideshows with audio, video. It allows us to provide people with more information about certain stories because in print, we only have a certain number of pages and a certain amount of space. That's not the case online. (personal communication, March 26, 2010)

Herald-Leader Editor Peter Baniak says reporters are expected to seek out that additional information while actively working on their traditional print story:

We encourage reporters to look for documents whenever possible that they can post so people can see the original document for themselves. ... We look for found video, like if we're doing a story about a political race, candidates nowadays will post their campaign commercial on their website. So we'll embed those with the story. ... If one of the Congressmen from Kentucky were to give a floor speech, [we would] link to that or embed the video from C-SPAN. (personal communication, March 26, 2010)

Individual reporter ability to contribute and/or produce online elements also contributes to many convergent journalism decisions on Kentucky.com and the other Herald-Leader websites. According to Johnson and Baniak, each reporter is expected to 
contribute something to the online product. Some reporters, however, appear to produce more online content than others.

Baniak describes one such reporter, a sports columnist, as "very comfortable" with technology. "He got a \$150 Flip Cam which he started carrying with him to games. He started doing just really short clips of player interviews after games. Frankly it grew kind of organically" (personal communication, March 26, 2010). Herald-Leader arts reporter Rich Copley also produces a lot of multimedia content for the website. He sees opportunity in convergent journalism: "To me a lot of the new media stuff has been really invigorating in thinking what other way can I tell these stories. And particularly for an arts and entertainment beat, I mean what is arts and entertainment? It's sight and sound" (personal communication, March 30, 2010).

Copley says he is self-trained in some photography, audio, and video. He also writes a blog for Lexgo.com. While Johnson praises Copley's work and hopes it will influence other reporters, he does not expect every reporter to reach that level of online production yet. "It depends on what kind of beat they're covering, it depends on what circumstances they're covering stories. We have some reporters who have blogs, but not every reporter does" (personal communication, March 26, 2010).

The Herald-Leader staff is also cognizant of the resources required to produce certain convergent journalism elements, especially video. Baniak says their approach to video is evolving:

When we started doing video on the web, you're talking about a photographer with a Handy Cam working with a reporter. We would do sort of long, almost documentary style videos, four minutes, five minutes. And what we found was 
that in some cases those would get hits. But by in large they were very timeintensive to produce. (personal communication, March 26, 2010)

Copley says he too has changed how much time he will invest into a web story:

I remember one assignment in particular, a Lexington ballet performance that I was previewing, where I went out with the intention of reporting a print story, taking still photos for that print story, and putting together a video. ... I walked away saying, 'you really tried to do too much in that one place. At least one of those you probably should have assigned a photographer to do the stills.' (personal communication, March 30, 2010) In the eyes of Herald-Leader management, online production efficiency is somewhat connected to audience traffic. Through a service called Omniture, the company can track how many views stories, slideshows, and videos are attracting. Johnson says there has to be the right balance of work output to audience input:

As every news organization faces tighter resources and smaller staffs, we want to make sure we're using our resources smartly. So while we have done some [multimedia] work in the past that is really nice, if it's not getting a lot of audience, then we need to look at it. It doesn't mean we're not going to do the story, we just want to make sure that were using all of our resources the right way. Because if you spend a lot of time doing one video that doesn't bring in a lot of audience, you may have spent that time better by doing more photos, that kind of thing. (personal communication, March 26, 2010)

Copley argues, however, that some stories deserve to be produced for the web regardless of generated traffic: 
There was one day a few weeks where we had three video clips that [a political reporter] had done with Governor Steve Beshear. Two of them were talking about legislative issues and one of them was about this NCAA [basketball tournament] predictions. And the NCAA predictions had three or four times more hits than the two legislative ones. It was like hundreds to several thousand hits. So it is all content dependent. (personal communication, March 30, 2010)

Finally, the Herald-Leader's local news competition also contributed to some decisions related to the posting of certain content on the websites. Johnson sees convergent journalism as an opportunity to uphold high standards of quality news reporting. "There is so much out there on the web now, but I think people know that the Herald-Leader and Kentucky.com and newspapers in general have a certain credibility" (personal communication, March 26, 2010). Johnson says that credibility is maintained by providing content that users cannot find anywhere else.

Many discussions Baniak has about online news elements are not about whether to post certain elements, but when to post them. Newsroom staff considers a story's exclusivity and the likely actions of other news outlets (such as TV stations) before posting some information on Kentucky.com, particularly court documents.

We know that if we post the story and the document before 4:30 pm [when the courthouse closes], the TV stations will then just download the document and do their own story without ever bothering to go to court. ... It's not gamesmanship, but there's a little bit of thought about the competitive environment we're in. (personal communication, March 26, 2010) 
$W T V Q-T V$

WTVQ News Director Doug Hogan sees resources as the primary factor in determining what news stories and elements end up on the wtvq.com website. The television station does not have an employee dedicated specifically to web production, thus all producers reporters, and assignment desk managers post stories to the website.

Hogan says he has noticed a shift in audience demand. "The marketplace is determining that if you're going to be competitive, you have to offer all these things: you have to offer the video, the additional information" (personal communication, March 29, 2010). But the lack of a dedicated web staff makes having a competitive website difficult for WTVQ. And if it there is a choice between updating the website or producing something for the upcoming TV newscast, Hogan says the traditional medium still wins out:

I think for us it comes down to an issue of having the manpower to devote the time, resources, and energy for one specific thing or the other. If we have all of our attention on the website, then we're going to be lacking on the evening news, and vice-versa. But we have to make a decision as far as TV station first, website second. (personal communication, March 29, 2010)

WTVQ's staffing situation also explains the sports video posted to the website. As noted in the content analysis, sports stories on wtvq.com were grouped together in three-to four-minute video files, basically a replication of the nightly sportscast. Because WTVQ only has two sports reporters, their work is mainly focused on gathering video for use during the newscasts. 
The amount of time a reporter has available to work on a story also affects the corresponding web story. Hogan cited a recent example of a story that took place two and a half hours away from the station:

So [the reporter] is going to have a five-hour investment just in drive time. She's not going to have a lot of time to get the story and then come back here and get it written and edited and get on air. So what we need to do in that situation is back here, get the information from her, and make sure we have the story updated on our website and promote the fact that we'll have it on our newscast for later in the evening. (personal communication, March 30, 2010)

Because WTVQ's priorities lie with the newscast, Hogan does not expect his staff to commit extra work time to updating the website. He says other staff needs to assist in the effort.

\section{WEKU-FM}

Similar to the situation at WTVQ, resources at WEKU - or a lack thereof greatly affect the amount of convergent journalism being produced for the station's website. Primary responsibility for posting news stories to the website falls on News Director Charles Compton, who then delegates a part-time student worker to complete most of the work:

We'll put a few headlines from today on the main [web] page. The user can then follow that to the newsroom section and there are a lot of stories listed there.

What are missing are links; tying the news to other resources that are out there.

While I think it would be great if our web editor started doing that, I only have her 
for 15 hours a week. And right now I would rather get as much news on the website as I can. (personal communication, March 23, 2010)

Compton says until a few months ago, WEKU was understaffed to produce all of its traditional programming, let alone prepare material for the website.

But WEKU Programming Director and Assistant General Manager Keith Neisler contends that lack of resources should not be an excuse for neglecting the website:

I think it's a reprioritization of the duties of your newsroom reporter. Do double duty. When you cut a wrap for your radio station, there's nothing to say you can't take an extra couple minutes and make an edit to make more online accessible and throw it up there. It takes a couple extra steps. (personal communication, March $22,2010)$

Compton admits he does not require his reporters to do much in the way of gathering or producing online journalism content. He describes himself and the other WEKU reporters as "a bunch of old guys ... trying to adapt to a new medium" (personal communication, March 23, 2010).

Neisler says an unwillingness or inability to learn how to use the Internet can greatly hinder convergent journalism goals: "I think part of the thing that we battle everyday is that we're talking about folks who are set in their ways in how things are done. Inertia from bureaucracy and processes of the past is probably [the] biggest roadblock to getting things accomplished" (personal communication, March 22, 2010). Neisler believes reporters must overcome any fear of change they may have in order to see the positive potential in learning online storytelling techniques. 
Question 4: Do certain types of news reports favor certain elements of convergent journalism?

Management at both the Herald-Leader and WTVQ has goals for the types of stories they feel should incorporate certain elements on their websites. The HeraldLeader emphasizes sports and breaking news stories as types of stories that should incorporate multimedia, particularly video. At the television station, emphasis is placed on enterprise feature reports as stories that should have multiple elements incorporated into the web version. WEKU does not have a preference in stories that it posts to its website.

\section{Lexington Herald-Leader}

Both Johnson and Baniak indicated in the interviews that convergent journalism storytelling techniques should be utilized for breaking news and sports stories. Baniak says the Internet allows for much faster dissemination of information:

When I came to work here fifteen years ago we didn't have any kind of vehicle if there was a breaking news situation like today, where there's been a bus crash in the morning; it would have taken us 24 hours before we could have communicated that to anyone. Today we were able to communicate it within minutes; we'll be able to update it all day long on the web, which is what we're doing. We can give people photos, we can tell them about it on Twitter, and tell them about it through email alerts and on their cell phones. (personal communication, March 26, 2010) 
Baniak says users now expect to get their news more quickly and with information that supplements-rather than replicates-the story. "That's why I think frankly doing short video clips is going to be more successful for us in the long run than doing, time intensive, production intensive videos because they augment the story and the reporting that you've already done."

Within the arts and entertainment beat, Copley says there appears to be some stories more conducive to added online content than others:

A lot of my early video pieces were about classical music events. And not to stereotype, because certainly there are a lot of people interested in classical music who are on the Internet, but the general Lexington classical music audience is still a big print newspaper audience. I would start getting people coming up to me and saying, "Why do you keep saying there are all these things on the web that you're not putting in the paper, and I can't see it?" (personal communication, March 30, 2010)

Copley now considers what his potential audience is for online content. If he anticipates a low online traffic rate compared to similar arts stories, Copley may reconsider what online elements he produces.

WTVQ-TV

The television product takes priority over the website in the WTVQ newsroom, but Doug Hogan says he expects to see a fully developed web story to correspond with the station's "franchise" pieces. These reports, such as "What's Cool in Your 
School" and "Kentucky's Back Roads," cover specialized topics. Hogan says the reporters and anchors who produce these specialty reports spend more time on them than they would a general assignment story. The stories are then "very prominently displayed" on wtvq.com, thus making it more important for the franchise pieces to have multiple convergent journalism elements, such as embedded video and links to other websites. (See Figure 7.)

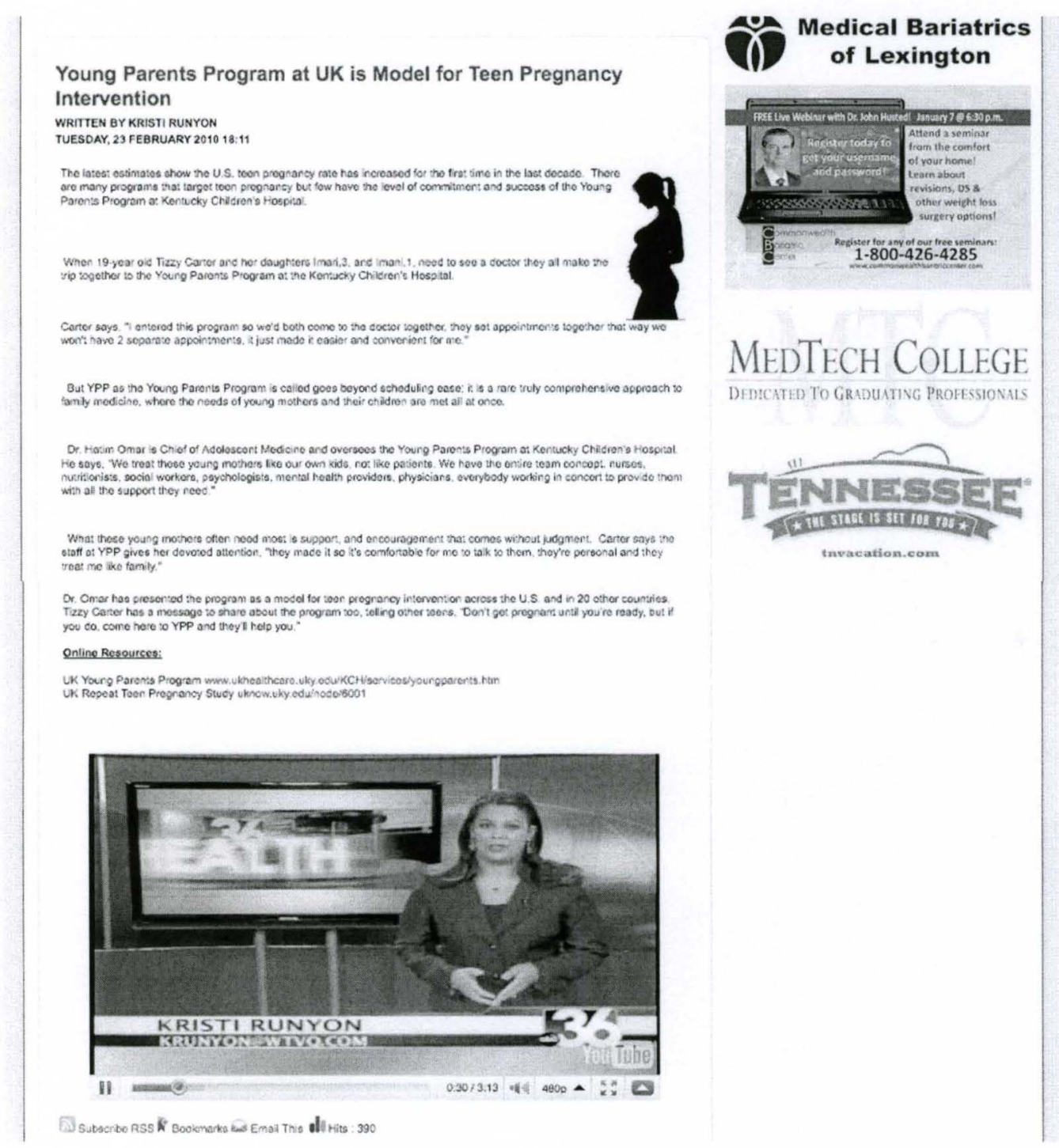

Figure 7. Screen capture of wtvq.com health story. This figure illustrates how a WTVQ "specialty story" incorporates text, embedded video, and links to other websites. 
WEKU-FM

Certain news stories by WEKU reporters do not appear more or less likely to be posted on weku.fm or to incorporate any particular online elements. If a reporter has produced a wrap, that audio will likely be replicated for the website. Neisler says he would like to see issue-specific blogs (such as political, education, and environment blogs) eventually connected to many of the WEKU stories. Such an effort would require additional work from the reporters and/or contributions from people outside the newsroom. But he adds, that type of convergent journalism cannot be produced at the expense of quality news reporting.

I don't want to just put the cart out there. You want to make sure you have grounding in content that's news. People trust us and that's all we have. If we sit there and put technology out there but don't think it through, [the audience] is going to go somewhere else (personal communication, March 22, 2010). Regardless of the convergent elements used, Neisler says WEKU needs to do a better job of getting feedback from its audience. Unlike the Herald-Leader and WTVQ, the radio station does not have a user comment section on its web stories. 


\section{DISCUSSION}

The three media organizations in this case study both differed and shared similarities in their approach to convergent journalism.

In terms of elements posted to the news outlets' respective websites, the HeraldLeader incorporated the greatest variety, including slideshows, audio, video, searchable databases, links, downloadable documents, and user comment sections. WTVQ-TV also incorporated some multimedia elements into its web stories, but not to the extent of the newspaper. WEKU-FM used the fewest number of components on its website.

The Herald-Leader's use of a wide array of convergent journalism storytelling techniques (especially when compared to other media organizations in the same market) can likely be attributed to availability of resources and philosophy of organization. The newspaper has a larger staff than WTVQ and WEKU, part of which is dedicated solely to web content. Furthermore, management at the Herald-Leader seem to place equal emphasis on production of the newspaper and the website, whereas WTVQ and WEKU remain primarily focused on their traditional formats.

All three news organizations engage in online social networking via Facebook and Twitter. This practice could indicate that while the newspaper, TV station, and radio station differ in their approach to online content, all see the Internet's potential to reach their audience. 
The web stories for each news organization greatly mirrored the original format. Even in the case of the Herald-Leader, of the hundreds of local news stories coded during the course of the study, only a handful incorporated unique elements for the web. Whether on Kentucky.com, wtvq.com, or weku.fm, the web stories were typically replications of the traditional format story. If a web story did utilize multimedia components, these elements were generally additional information for the web user. Of course, replication of news stories on the web is not a bad thing; many news consumers may go to a news outlet's website to re-read, re-watch, or share a story they originally came across in its traditional form. To echo the belief of Herald-Leader Editor Peter Baniak, multimedia content should serve as a supplement, rather than tell the whole story (personal communication, March 26, 2010). Still, it is concerning that more "supplementing" is not being done on media websites, particularly in the case of wtvq.com and weku.fm.

One reason for this lack of additional content was revealed in the in-depth interviews. Both WTVQ and WEKU lack personnel and budget resources to fully tap the potential of Internet storytelling.

Posting online content is a shared responsibility at WTVQ; no fulltime employee is designated to work solely on the website. Thus, while WTVQ's staff all understands the basics of online storytelling, they do not have an easily accessible "expert" to guide them or to establish a unified web story format. Several anchors at the station are taking advantage of the Internet to blog about their non-news interests and hobbies, but these blogs do not appear to be promoted very well. 
Furthermore, News Director Doug Hogan has a different expectation of his reporters than Herald-Leader management has of theirs. Instead of directing all staff to contribute additional content for the website to correspond with each local story, Hogan takes an individualized and situational approach to each reporter and his/her work assignment. This approach may be an effective way to manage employees, but it does not maximize the content on wtvq.com.

At the radio station, WEKU News Director Charles Compton also prefers to have his news reporters focus solely on gathering traditional radio stories. He too lacks a fulltime professional web editor on staff. Perhaps if the reporters were further trained on how to edit the weku.fm website, they would have a better understanding of multimedia content and be more apt to seek out additional information (such as photographs, document files, links) to enhance their traditional radio reports on the web.

Based on the information gathered in this case study, it is difficult to say whether one type of news story is more likely or suitable to utilize multimedia than another. Use of additional online content seems to largely depend on the priorities and philosophy of each individual news organization. For the Herald-Leader, gathering web video is a priority for breaking news and sports stories. At WTVQ, emphasis is placed on specialty "franchise" reports for including multiple web elements.

By answering the four research questions, this case study sought to discover the underlying motivations for news organizations engaging in convergent journalism on the web. Why have a website at all? Each news outlet identified advertising/marketing and the need to keep up with technology as contributing factors to having an online presence. However, management at the Herald-Leader, WTVQ, and WEKU said the primary goal 
of their websites is to deliver information to the news consumer. According to Johnson (personal communication, March 26, 2010), "our job is to look at ourselves as we provide news and information to people, and we need to provide it in whatever format they want to receive it, whether that's in print, whether that's online." This finding is promising; although each studied news outlet uses the Internet in a slightly different way to convey news stories, research subjects indicated their focus remains on producing quality journalism. It is this commitment to good storytelling that Baniak says will ultimately allow media to maintain their identity in a digital world, where traditional media boundaries are blurred:

The market wants what the market wants. ... Look at the phenomenal success of YouTube. People, readers, viewers, whatever you want to call them have come to expect that there's going to be more than just print. And I think there are a lot of people who love to read a good story. We have worked hard to try and preserve that in the paper, just good storytelling, good written-word storytelling. I am a newspaper purist in that sense. (personal communication, March 26, 2010)

Despite their good intentions, news organizations are not using the Internet to its fullest potential. Hyperlinks, video, and audio are posted to only a handful of stories on Kentucky.com. WTVQ and WEKU, because they are broadcast media that are already familiar working with audio/visual technology, would appear to have an advantage at producing multimedia content for their websites. However, they are significantly behind the newspaper's efforts. Any video or audio that is posted on wtvq.com or weku.fm simply replicated the traditional media report. 
It is not a matter of management at the Herald-Leader, WTVQ, and WEKU being unaware or ignorant of the Internet's storytelling potential; indeed, all interview subjects identified what they believed were their respective website's strengths and weaknesses. The biggest strength of the Herald-Leader's convergence efforts is their ability to post and update information on their website quickly. But Editor Peter Baniak says more can be accomplished:

Do I think we are fully capturing the potential of online? No. Do I think that any media company is? No. I think there are more opportunities for us to give readers opportunities to interact. I think we could do more video and audio. We could do more databases and innovate more. (personal communication, March 26, 2010) At WTVQ and WEKU, there is a discord between goals and reality. One of Doug Hogan's goals is hiring specialized web staff:

We are living in an age now where every TV newsroom should have web content managers, should have even web content assignment editors. Television stations and newsrooms now will have to devote those necessary resources in order to be competitive and in order to give the viewers what they're accustomed to. (personal communication, March 29, 2010)

Unfortunately for Hogan, WTVQ appeared (at the time of the interview) to have no plans to hire web-only staff.

At the radio station, there appears to be not only a discord between goals and reality, but also a discord as to what the goals actually are. Programming Director Keith Neisler wants to see more individual understanding and participation in producing web content: "I still have people on staff that don't understand what Twitter is, and that's not 
good. I'm really big into Twitter and Facebook. I love it because I see the potential of it" (personal communication, March 22, 2010). For News Director Charles Compton, however, the main goal for the website is getting content posted accurately:

In order to get my little head around it, I perceive the website as a high tech newspaper. So the articles that are there need to be easily accessible the user, easily understandable by the user. I gotta be able to look at it, and understand what's being said. But I guess it's efficient and effective if a user has at least a portion of his or her curiosity satisfied by going there. (personal communication, March 23, 2010)

More than a decade has passed since journalism organizations first began developing news websites, but use of online storytelling techniques has been slow to catch on. Technology continues to evolve and will not wait for traditional media. It is imperative that media organizations continually evaluate their convergent practices while still producing quality journalism. Management and reporters will need to understand how to use changing equipment and software, and more training will be necessary. If newsrooms are to change their priorities and attitudes toward convergent journalism, reporters like Rich Copley, who embraces new technologies and wants to work them, will need to become more of the norm rather than the exception.

The circumstances and processes documented in this case study appear to fit into Erdal's (2009) model of cross-media journalism. On the work axis, the Herald-Leader and WTVQ journalists who contributed content to the website were in some cases engaging in Erdal's first category of single-reporter multiplatform journalism, while evidence of Erdal's third category of multiplatform orchestration was apparent in other 
stories, especially in the case of WEKU. On the content axis of the convergence model, most of the web stories produced by the three media organizations involved in this case study generally fell into the category of augmentation, or the category of reversioning. Cases of additional content being incorporated to a web story appeared to fit the definition of what Erdal classifies as recombination, or raw material being reworked for a different platform.

Rather than focusing on large media markets where companies may have access to greater resources, this case study explored the convergent journalism practices of three different media in a medium-sized market. This study was limited in that interview subjects were primarily members of news organization management. The author would have liked to have the perspective of more news reporters, particularly at WTVQ. Furthermore, a longer content analysis period could have yielded a better description of how news organizations incorporate multimedia elements into web stories.

It would be interesting to return to the Herald-Leader, WTVQ, and WEKU in the future to see how their websites have or have not changed. Further convergent journalism research should explore the affect of the economy on newsroom web resources, how news organizations in varying market sizes make use of multimedia, and what effect multimedia has on news audiences. 


\section{REFERENCES}

APB Online to post entire Frank Sinatra FBI file immediately upon release today. (1998, Dec 8) Business Wire. Retrieved from http://findarticles.com/p/articles/mi_m0EIN/is_1998_Dec_8/ai_53364989/

Audit Bureau of Circulations. (2009). eCirc. Retrieved from

http://abcas3.accessabc.com/ecirc/index.html

Baker, C.E. (2002). Media, markets, and democracy. Cambridge, UK: Cambridge University Press.

Carlson, D. (2003). The history of online journalism. In K. Kawamoto (Ed.), Digital journalism (31-55). Lanham, MD: Rowman \& Littlefield.

Dailey, L., Demo, L., \& Spillman, M. (2005). The convergence continuum: A model for studying collaboration between media newsrooms. Atlantic Journal of Communication, 13(3) 150-168.

Duhe, S.F., Mortimer, M.M., \& Chow, S.S. (2004). Convergence in North American TV newsrooms: A nationwide look. Convergence, 10(2), 81-104.

Dupagne, M., \& Garrison, B. (2006). The meaning and influence of convergence. Journalism Studies, 7(2), 237-255. 
Eggerton, J. (2008, May 15). Senate votes to block FCC's cross-ownership rule change. Broadcasting \& Cable. Retrieved from http://www.broadcastingcable.com/article/CA6561506.html

Eggerton, J. (2009, Dec. 18). Court asks FCC to defend media-ownership rule stay. Broadcasting \& Cable. Retrieved from http://www.broadcastingcable.com/article/441157Court_Asks_FCC_to_Defend_Media_Ownership_Rule_Stay.php?rssid=20065

Erdal, I. J. (2009). Repurposing of content in multi-platform news production: Towards a typology of cross-media journalism. Journalism Practice, 3(2), 178-195.

Fahmy, S. (2008). How online journalists rank importance of news skills. Newspaper Research Journal 29(2), 23-39.

Federal Communications Commission. (2010, March 23). Statement of Commissioner Robert M. McDowell on Third Circuit order advancing court review of the 2007 media ownership decision (Doc. 297049A1), [Press Release]. Washington, DC: U.S. Government Printing Office.

García Avilés, J.A., \& Carvajal, M. (2009). Integrated and cross-media newsroom convergence. Convergence, 14(2), 221-239.

Gordon, R. (2003). The meanings and implications of convergence. In K. Kawamoto (Ed.), Digital journalism (57-73). Lanham, MD: Rowman \& Littlefield. 
Gunter, B. (2003). News and the net. Mahwah, NJ: Lawrence Erlbaum Associates.

Haythornthwaite, C. \& Wellman, B. (2002). The Internet in everyday life. In B. Wellman \& C. Haythornthwaite (Eds.), The Internet in everyday life (pp. 3-41). Malden, MA: Blackwell.

Holsti, O.R. (1969). Content analysis for the social sciences and humanities. Reading, MA: Addison-Wesley Publishing.

Huang, E., Davison, K., Shreve, S., Davis, T., Bettendorf, E., \& Nair, A. (2006). Bridging newsrooms and classrooms: Preparing the next generation of journalists for converged media. Journalism \& Communication Monographs 8(3), 221-262.

Huang, E., Rademakers, L., Fayemiwo, M.A., \& Dunlap, L. (2004). Converged journalism and quality: A case study of The Tampa Tribune news stories. Convergence, 10(4), 73-90.

Ives, N. (2010). Print veterans looking to go digital learn it's tough to make the switch. Advertising Age, 81(12), 3-22. Retrieved from Communication \& Mass Media Complete database.

Kawamoto, K. (2003). Digital journalism. Lanham, MD: Rowman \& Littlefield. Krippendorff, K. (1980). Content analysis: An introduction to its methodology. Beverly Hills, CA: Sage. 
Lacy, S., Riffe, D., \& Randle, Q. (1998). Sample size in multi-year content analyses of monthly consumer magazines. Journalism \& Mass Communication Quarterly, $75(2), 408-417$.

Lawson-Borders, G. (2003). Integrating new media and old media: Seven observations of convergence as a strategy for best practices in media organizations. JMM: The International Journal of Media Management, 5(1), 39-46.

Lawson-Borders, G. (2006). Media organizations and convergence: Case studies of media convergence pioneers. Mahwah, NJ: Lawrence Erlbaum Associates.

Lindlof, T.R., \& Taylor, B.C. (2002). Qualitative communication research methods $\left(2^{\text {nd }}\right.$ ed.). Thousand Oaks, CA: Sage.

Lipsey, M.W., \& Wilson, D.B. (2001). Practical meta-analysis. Thousand Oaks, CA: Sage.

Nassiri, J. (2009, September). RTNDA set to make historic name change on October 13. Communicator. Retrieved from http://www.rtdna.org/pages/posts/rtnda-set-tomake-historic-name-change-on-october-13675.php

Neuman, W.R. (1991). The future of the mass audience. New York: Cambridge University Press. 
Nielsen Company. (2009). Local television market universe estimates: Comparisons of 2008-09 and 2009-10 market ranks [PDF document]. Retrieved from http://blog.nielsen.com/nielsenwire/wp-content/uploads/2009/08/2009-2010-dmaranks.pdf

Pavlik, J.V. (2001). Journalism and new media. New York: Columbia University Press.

Pew Internet and American Life Project. (2010, March 1). Understanding the participatory news consumer. Retrieved from http://www.pewinternet.org/Reports/2010/Online-News.aspx?r=1

Quinn, S. (2005). Convergence's fundamental question. Journalism Studies, 6(1), 29-38. Quinn, S. (2006). Conversations on convergence: Insiders views on news production in the $21^{\text {st }}$ century. New York: Peter Lang Publishing.

Riffe, D., Lacy, S., Nagovan, J., \& Burkum, L. (1996). The effectiveness of simple and stratified random sampling in broadcast news content analysis. Journalism \& Mass Communication Quarterly, 73(1), 159-168.

Salwen, M.B., Garrison, B., \& Driscoll, P.D. (2005). The baseline survey projects: Exploring questions. In M.B. Salwen, B. Garrison, \& P.D. Driscoll (Eds.), Online news and the public (pp. 121-146). Mahwah, NJ: Lawrence Erlbaum Associates.

Singer, J.B. (2004). Strange bedfellows? The diffusion of convergence in four news organizations. Journalism Studies, 5(1), 3-18. 
Smith, L.K. Tanner, A.H., \& Duhé, S.F. (2007). Convergence concerns in local television: Conflicting views from the newsroom. Journal of Broadcasting \& Electronic Media, 51(4), 555-574.

Thurman, N., \& Lupton, B. (2008). Convergence calls: Multimedia storytelling at British news websites. Convergence, 14(4), 439-455.

WEKU. (2010). About WEKU. Retrieved from http://www.weku.fm/about.htm Yin, R. K. (1994). Case study research: Design and methods ( $2^{\text {nd }}$ ed.). Thousand Oaks, CA: Sage. 


\section{CURRICULUM VITAE}

NAME: Brenna Loraine Angel

ADDRESS: 2020 Armstrong Mill Rd.

Apt. 532

Lexington, KY 40515

DOB: $\quad$ November 11, 1984

EDUCATION

\& TRAINING: $\quad$ B.A., Broadcast Journalism

Western Kentucky University

2003-2006

M.A., Communication

University of Louisville

2007-2010

AWARDS: Best Radio Reporter

Kentucky Associated Press

2010

National Radio Champion

Hearst Journalism Foundation

2006 